\title{
Tackling the epidemic of childhood obesity
}

\author{
Louise A. Baur PhD
}

$\infty$ See related research paper by Harris and colleagues, page 719

$\mathrm{T}$ he rising prevalence of childhood obesity in most developed countries is well recognized, ${ }^{1}$ as are the many short- and long-term complications that can occur as a result. ${ }^{2}$ The past decade has seen a rapid growth in research into various aspects of this epidemic. However, in most countries, there has been a far slower response in terms of the number of funded policies and services aimed at preventing and treating childhood obesity. What strategies should be implemented?

In this issue of $C M A J$, Harris and colleagues ${ }^{3}$ report the results of a systematic review of randomized controlled trials and controlled clinical trials designed to determine the effect of school-based physical activity interventions on body mass index among children. ${ }^{3}$ The 18 included studies mainly targeted elementary school children and covered a range of interventions, including moderate to vigorous physical activity, increased school time for exercise, and weight bearing exercises. Their meta-analysis showed that specific physical activity interventions did not result in additional improvements in body mass index compared with existing physical activity curricula. Several explanations for this lack of association are suggested by the authors, including an insufficient "dose" of physical activity, possible poor adherence to the planned interventions, inherent limitations of using body mass index

Box 1: Approaches to treatment of childhood obesity $^{7,8}$

- Changes to the whole familys lifestyle

- Developmentally appropriate approaches, with parents being the "agents of change" for younger children ${ }^{9}$

- Long-term behavioural changes, including strategies such as monitoring behaviour, setting and reviewing goals, rewarding successful changes in behaviour and controlling the environment

- Changes in dietary intake, including modified eating patterns, parental modelling of healthy food choices, consumption of lower-fat and lower-energy foods, increased vegetable intake, decreased portion sizes and reduced intake of sweetened drinks

- Increased physical activity through unstructured activity, active transport and access to play equipment, and parental role-modelling of an active lifestyle

- Decreased sedentary behaviour through limiting television and computer time to $<2$ hours per day

- Use of nonconventional therapies, such as pharmacotherapy, as an adjunct to support lifestyle changes for adolescents who have moderate to severe obesity

\section{Key points}

- School-based physical-activity programs do not decrease the prevalence of childhood obesity, but they are associated with a range of other health benefits.

- Multilevel, whole-society strategies for physical activity and food intake are needed to tackle obesity.

- Children and young people affected by obesity need effective treatment interventions that include family physicians and pediatricians.

- No health system has implemented a sustainable and coordinated model of delivery for services for obesity prevention and treatment.

as a measure of body composition and the possibility that dietary modification may have a greater influence on body composition than physical activity.

Importantly, the authors comment that the results of their systematic review should not negate the importance of promoting physical activity in schools. They rightly point out the many other health benefits from school-based physical activity, including improvements in bone mineral density, blood pressure, lean muscle mass and aerobic capacity. However, their results raise questions about tackling the epidemic of childhood obesity: What is the optimal approach to prevent obesity? How can children already affected by obesity best be helped?

A 2007 governmental report from the United Kingdom describes obesity as a "complex system," with an individual's energy intake and energy output, and hence weight, being influenced by a range of highly interconnected factors. ${ }^{4}$ These factors can operate at the individual level (e.g., genetic predisposition to obesity, level of satiety, stress level, learned activity patterns) or at the broader environmental and societal level (e.g., how suitable an area is for walking, abundance and price of food, portion sizes, societal pressure to consume, food marketing). No simple or short-term changes, such as a physical activity intervention for a limited length of time in the school curriculum, can be expected to influence the prevalence of obesity. Such an approach can be described as "the futility of isolated initiatives."

Instead, a case can be made for investment in a range of community-based cross-disciplinary long-term strategies that work at multiple levels. Examples might include the provision of healthy school meals, improved urban planning (e.g., provision of bicycle lanes and increased accessibility of public transportation), control of the advertising of foods with high fat, salt and sugar contents, and subsidies on vegetables and fruit for certain groups (e.g., child care centres and schools).

Louise Baur is with the University of Sydney and The Children's Hospital at Westmead, Sydney, Australia. 
This system-wide approach makes sense, but it will require a great deal of political will, community ownership and governmental, societal and industrial commitment to bring it into effect. Recent evidence suggesting that the obesity prevalence rates in France plateaued following a range of multilevel interventions provides a glimmer of hope for other countries, even those that have a more entrenched "obesogenic" environment. ${ }^{5}$

Appropriate investment in the prevention of obesity is only one part of a response to childhood obesity. Given the large number of affected children in many countries, there is an urgent need for the provision of effective treatment services. This is where there is a major role for physicians, particularly those working in primary care or pediatrics. For example, regular monitoring of children's height and weight and the use of body mass index-for age charts can help physicians to recognize overweight or obese children, and the issue can be raised sensitively with the children or their families. ${ }^{6}$ The principles of childhood obesity treatment are well established (Box 1).

Despite our increased understanding of the elements of obesity treatment, no health system has yet developed a sustainable and coordinated model of clinical service delivery for treatment of obesity that allows access for children and their families to affordable and effective primary, secondary and tertiary programs of care. Nor does any health system have a health workforce that is, as yet, sufficiently trained to cope with the clinical load of obese children and their families. Such a situation raises the urgent need for clinicians, researchers and health administrators to develop, evaluate and implement workable approaches to providing effective clinical care for the many children and young people affected by obesity.

Competing interests: None declared.

\section{REFERENCES}

1. Wang Y, Lobstein T. Worldwide trends in childhood overweight and obesity. Int J Pediatr Obes 2006;1:11-25.

2. Lobstein T, Baur L, Uauy R; for the IASO International Obesity TaskForce. Obesity in children and young people: a crisis in public health. Obes Rev 2004;5 (Suppl 1):4-104.

3. Harris KC, Kuramoto LK, Schulzer M, et al. Effect of school-based physical activity interventions on body mass index in children: a meta-analysis. CMAJ 2009;180:719-26.

4. Butland B, Jebb S, Kopelman P, et al. Foresight. Tackling obesities: future choices — project report. London (UK): Government Office for Science; 2007. Available: www.foresight.gov.uk/Obesity/17.pdf (accessed 2009 Feb. 25).

5. Czernichow S, Maillard-Teyssier L, Vergnaud AC, et al. Trend towards a stabilization of obesity prevalence in France: a population-based study, 1995-2005 [abstract]. Int J Obes 2008;32(Suppl 1):S32.

6. Kipping RR, Jago R, Lawlor DA. Obesity in children. Part 1: Epidemiology, measurement, risk factors, and screening. BMJ 2008;337:a1824.

7. Oude Luttikhuis H, Baur L, Jansen H, et al. Interventions for treating obesity in children. Cochrane Database Syst Rev 2009;(1):CD001872.

8. Dietz WH, Robinson TN. Clinical practice. Overweight children and adolescents. N Engl J Med 2005;352:2100-9.

9. Golan M, Crow S. Targeting parents exclusively in the treatment of childhood obesity: long-term results. Obes Res 2004;12:357-61.

Correspondence to: Dr. Louise Baur, University of Sydney Clinical School, The Children's Hospital at Westmead, Locked Bag 4001, Westmead NSW 2145, Australia; fax: 61-2-9845-3389; louiseb3@chw.edu.au 